\title{
Estimation of the maximum allowable drift at the top of a shear wall (within elastic limits)
}

\author{
M. Khouri \\ Department of Civil Engineering, Lebanese University, Lebanon
}

\begin{abstract}
There is a considerable uncertainty regarding the evaluation of the maximum allowable story drift as well as the maximum allowable lateral drift at the top of a building. Various seismic codes suggest values that range from $h / 50$ to $h / 2000$ where $\mathrm{h}$ is the height of a building. This paper reviews the maximum allowable drift presented in various seismic codes and uses structural dynamics along with the finite element method to suggest a formula that can be used to determine the maximum allowable drift at the top of a shear wall based on the maximum allowable strain values in that shear wall. This formula provides an elastic limit for the drift after which the designer knows that his reinforced concrete section is going into the plastic region. In comparing the results generated by the suggested formula with the drift values suggested by other codes, it can be observed that the results are very close to the values obtained by the use of the French code PS92 and far from the values suggested by UBC and IBC.
\end{abstract}

\section{Introduction}

A shear wall is one of the main structural elements in a reinforced concrete building. It is constructed to support mainly the lateral forces due to wind or earthquakes. Under these loads, the structure will have a lateral displacement (what is known nowadays as Drift) the magnitude of which is defined by the movement of the lateral load resisting elements (shear walls). The question remains: what is the allowable drift at the top of a given shear wall? And consequently what is the maximum allowable drift at the top of a building?

Many investigators have suggested values for maximum displacement at the top of buildings. These values range from taking $h / 50$ where $h$ is the height of the building as suggested by The Uniform Building Code (UBC97) [1] and 
International Building Code (IBC2006) [2] to choosing about $\mathrm{h} / 2000$ as in The Lebanese Code [3].

This study makes use of the finite element method [4,5] to evaluate the displacement at the top of a shear wall and suggests an equation that can be followed in determining the maximum allowable drift. It is divided into five parts:

* In the first part, the stiffness matrix of a shear wall is determined by making the assumption that a shear wall is a vertical beam in flexure with constant stiffness throughout its height.

* In the second part, a relation between maximum displacement and the base shear is found using the force-displacement relationship.

* In the third part, expressions for displacement and relative displacement at any level are determined.

* In the fourth part, a general formula for the strain at the $i^{\text {th }}$ story along the shear wall is computed and maximum strain values are found.

* In the last part, a combination of the results is used to obtain a relation between maximum displacement at the top of the shear wall and maximum strain at the bottom of the shear wall. Consequently, an expression for the allowable drift at the top of the building is determined and represented in the graphs later. Comparison between the suggested formula and various seismic codes is then done.

Table 1: $\quad$ Inter-story drift limits for various seismic codes.

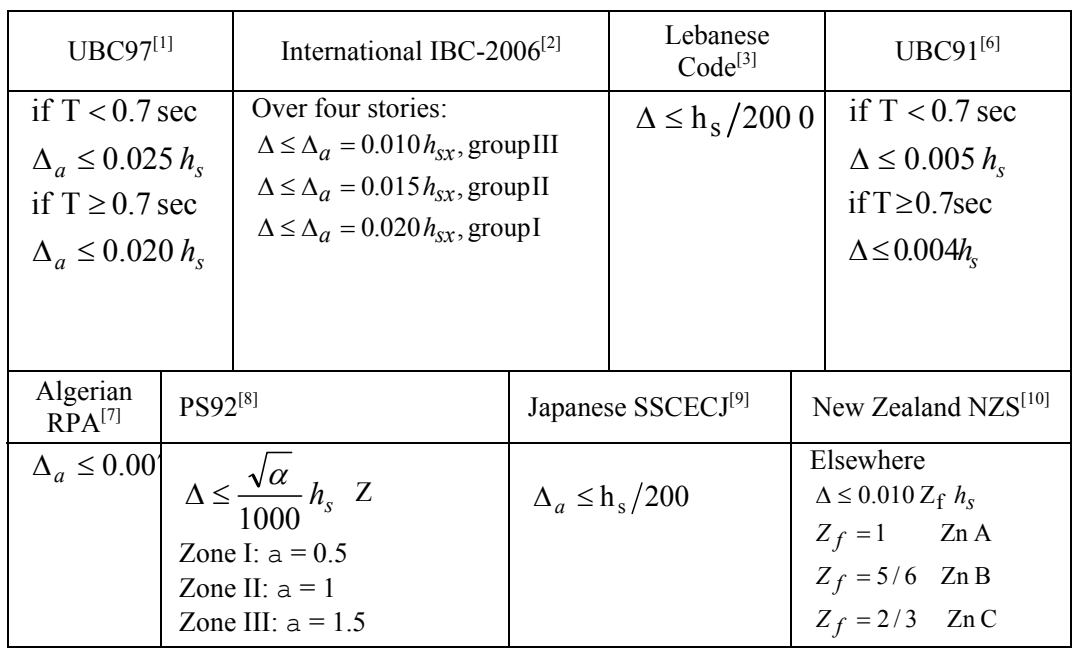

\section{Background}

Many investigators and seismic codes suggest values for maximum allowable story drift or maximum allowable displacement at the top of a building but these values differ significantly. A comparison of these values is presented in Table 1. 
As can be seen from this table, drift values vary between $\mathrm{h} / 50$ and $\mathrm{h} / 2000$ and the questions that can be asked are: why are these differences in the estimation of the lateral drift? On what basis these estimations are made? How can we use actual structural behavior to determine maximum allowable drift? The following article explains a procedure to estimate the maximum allowable drift between stories and consequently determines the same at the top of a building or a shear wall.

\section{Assembly of matrices (shear building)}

Consider a regular inclined beam as in Figure 1. The objective is to generate the stiffness matrix for a shear building.

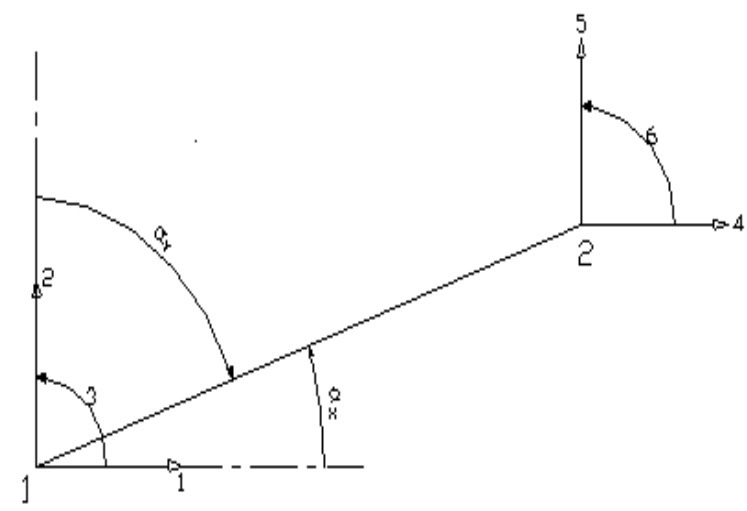

Figure 1: $\quad$ Inclined beam with $\alpha_{\mathrm{x}}$ and $\alpha_{\mathrm{y}}$ angles. (Three displacements at each node: horizontal, vertical and rotational.)

To represent a shear wall, a vertical beam in flexure is assumed which means that only the flexural effects of the element are considered and the horizontal displacements are only due to flexure, where the rotation of the nodes are taken equal to zero.

Where:

$$
\mathrm{k}=\frac{\mathrm{EI}}{\mathrm{L}^{3}}\left[\begin{array}{cccccc}
12 \mu^{2} & -12 \lambda^{2} & -6 L \mu & -12 \mu^{2} & 12 \lambda^{2} & -6 \mathrm{~L} \mu \\
-12 \lambda^{2} & 12 \lambda^{2} & 6 \mathrm{~L} \lambda & 12 \lambda^{2} & -12 \lambda^{2} & 6 \mathrm{~L} \lambda \\
-6 L & 6 \mathrm{~L} \lambda & 4 \mathrm{~L}^{2} & 6 L \mu & -6 \mathrm{~L} \lambda & 2 \mathrm{~L}^{2} \\
-12 \mu^{2} & 12 \lambda^{2} & 6 L \mu & 12 \mu^{2} & -12 \lambda^{2} & 6 L \mu \\
12 \lambda^{2} & -12 \lambda^{2} & -6 \mathrm{~L} \lambda & -12 \lambda^{2} & 12 \lambda^{2} & -6 \mathrm{~L} \lambda \\
-6 L \mu & 6 \mathrm{~L} \lambda & 2 \mathrm{~L}^{2} & 6 L \mu & -6 \mathrm{~L} \lambda & 4 \mathrm{~L}^{2}
\end{array}\right]
$$

$\lambda=\cos \alpha_{\mathrm{x}}$ and $\mu=\cos \alpha_{\mathrm{y}}$,

$\mathrm{L}$ is the length of the beam-column,

$\mathrm{E}$ is the modulus of elasticity,

$\mathrm{I}$ is the moment of inertia of the beam-column.

$\lambda=\cos \alpha_{\mathrm{x}}=\cos (\pi / 2)=0$, and $\mu=\cos \alpha_{\mathrm{y}}=\cos (0)=1$. 


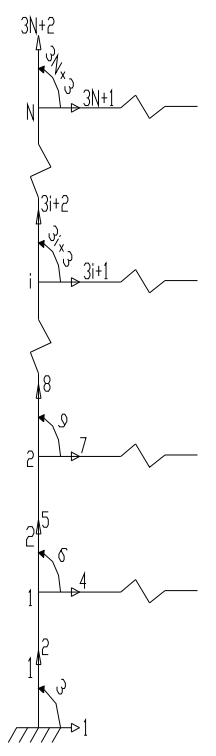

Figure 2: $\quad$ Representation of an N-story building.

Substituting $\lambda$ and $\mu$ by their values in eqn (1), and using boundary conditions $\mathrm{q} 3=\mathrm{q} 6=0$ to assume no rotation, and $\mathrm{F} 2=\mathrm{F} 5=0$ to assume no axial force, and replacing in $\{\mathrm{F}\}=[\mathrm{K}]\{\mathrm{q}\}$, the following matrix can be obtained,

$$
\left\{\begin{array}{l}
\mathrm{F}_{1} \\
\mathrm{~F}_{4}
\end{array}\right\}=\frac{\mathrm{EI}}{\mathrm{L}^{3}}\left[\begin{array}{cc}
12 & -12 \\
-12 & 12
\end{array}\right]\left\{\begin{array}{l}
\mathrm{q}_{1} \\
\mathrm{q}_{4}
\end{array}\right\}
$$

From Figure 2, eqn (3) can be assembled relative to degrees of freedom 4, 7, $\ldots, 3 \mathrm{j}+1 \ldots 3(\mathrm{~N}-1)+1,3 \mathrm{~N}+1$. Also constant stiffness is assumed in all stories where $\mathrm{k}^{(1)}=\mathrm{k}^{(2)}=\ldots=\mathrm{k}^{(\mathrm{N})}=\mathrm{k}$.

The system of $\mathrm{N}$ degrees of freedom will be of the following form:

$$
\left\{\begin{array}{c}
\mathrm{F}_{4} \\
\mathrm{~F}_{7} \\
\vdots \\
\vdots \\
\mathrm{F}_{3 \mathrm{j}+1} \\
\vdots \\
\vdots \\
\mathrm{F}_{3(\mathrm{~N}-1)+1} \\
\mathrm{~F}_{3 \mathrm{~N}+1}
\end{array}\right\}=\mathrm{k}\left[\begin{array}{ccccccccc}
2 & -1 & 0 & \ldots & \ldots & \ldots & \ldots & 0 & 0 \\
-1 & 2 & -1 & 0 & \ldots & \ldots & \ldots & 0 & 0 \\
0 & \ddots & \ddots & \ddots & 0 & \ldots & \ldots & \ldots & 0 \\
0 & 0 & \ddots & \ddots & \ddots & 0 & \ldots & \ldots & 0 \\
0 & \ldots & 0 & -1 & 2 & -1 & 0 & \ldots & 0 \\
0 & \ldots & \ldots & 0 & \ddots & \ddots & \ddots & 0 & 0 \\
0 & \ldots & \ldots & \ldots & 0 & \ddots & \ddots & \ddots & 0 \\
0 & 0 & \ldots & \ldots & \ldots & 0 & -1 & 2 & -1 \\
0 & 0 & \ldots & \ldots & \ldots & \ldots & 0 & -1 & 1
\end{array}\right] \cdot\left\{\begin{array}{c}
\mathrm{q}_{4} \\
\mathrm{q}_{7} \\
\vdots \\
\vdots \\
\mathrm{q}_{3 \mathrm{j}+1} \\
\vdots \\
\vdots \\
\mathrm{q}_{3(\mathrm{~N}-1)+1} \\
\mathrm{q}_{3 \mathrm{~N}+1}
\end{array}\right\}
$$

where, $k$ is the stiffness of one story $=\sum_{j=1}^{n} 12 \frac{E_{j} I_{j}}{L^{3}}$ 


\section{Relation between maximum drift and base shear}

To find a relation between the total base shear $\mathrm{V}$, stiffness $\mathrm{k}$ and maximum displacement $\Delta$ for $\mathrm{N}$ stories structure, a triangular distribution of $\mathrm{V}$ is assumed [11]. Please note that the base shear can be found by any procedure or any seismic code. This distribution of $\mathrm{V}$ gives a formula of the applied force $\mathrm{F}_{\mathrm{i}}$ at every level $\mathrm{i}$ of the structure as a function of $\mathrm{N}$,

$$
\begin{gathered}
\mathrm{F}_{\mathrm{i}}=\frac{2 \mathrm{iV}}{\mathrm{N}(\mathrm{N}+1)} \quad \text { and } \mathrm{F}=\mathrm{k} . \mathrm{q} \Rightarrow \mathrm{q}=\mathrm{k}^{-1} . \mathrm{F}, \text { where } \\
\mathrm{q}=\left\{\begin{array}{c}
\mathrm{q}_{4} \\
\mathrm{q}_{7} \\
\vdots \\
\vdots \\
\mathrm{q}_{3 i+1} \\
\vdots \\
\vdots \\
\mathrm{q}_{3 \mathrm{~N}+1}=\Delta
\end{array}\right\}=\frac{2 \mathrm{~V}}{\mathrm{~N}(\mathrm{~N}+1)} \frac{1}{\mathrm{k}} \cdot\left[\begin{array}{cccccccc}
1 & 1 & \ldots & \ldots & 1 & \ldots & \ldots & 1 \\
1 & 2 & \ldots & \ldots & 2 & \ldots & \ldots & 2 \\
\vdots & \vdots & \ddots & & \vdots & \ddots & & \vdots \\
\vdots & \vdots & & \ddots & \vdots & & \ddots & \vdots \\
1 & 2 & \ldots & \ldots & \mathrm{i} & & & \mathrm{i} \\
\vdots & \vdots & \ddots & & \vdots & \ddots & & \vdots \\
\vdots & \vdots & & \ddots & \vdots & & \ddots & \vdots \\
1 & 2 & \ldots & \ldots & \mathrm{i} & \ldots & \ldots & \mathrm{N}
\end{array}\right]\left\{\begin{array}{c}
1 \\
2 \\
\vdots \\
\vdots \\
\mathrm{i} \\
\vdots \\
\vdots \\
\mathrm{N}
\end{array}\right\} \\
\Delta=\frac{2 V}{N(N+1)} \frac{1}{k} \sum_{i=1}^{i=N} i^{2}, \text { but } \sum_{\mathrm{i}=1}^{\mathrm{i}=\mathrm{N}} \mathrm{i}^{2}=\frac{\mathrm{N}(\mathrm{N}+1)(2 \mathrm{~N}+1)}{6},
\end{gathered}
$$

Therefore, $\Delta=\frac{(2 \mathrm{~N}+1) \mathrm{V}}{3} \frac{1}{\mathrm{k}}$,

The formula for the base shear becomes $\quad \mathrm{V}=\frac{3}{2 \mathrm{~N}+1} \mathrm{k} \Delta$

\section{Displacement and relative displacement values}

The displacement $\mathrm{q}_{\mathrm{i}}=(\mathrm{V} / \mathrm{k}) \mathrm{X}_{\mathrm{i}}$, and let $\mathrm{X}=\sum_{i=1}^{N} \mathrm{i}=\frac{\mathrm{N}(\mathrm{N}+1)}{2}, \Rightarrow$

$$
\mathrm{q}=\mathrm{k}^{-1} \cdot \mathrm{F}=\left[\begin{array}{cccccccc}
1 & 1 & \ldots & \ldots & 1 & \ldots & \ldots & 1 \\
1 & 2 & \ldots & \ldots & 2 & \ldots & \ldots & 2 \\
\vdots & \vdots & \ddots & & \vdots & \ddots & & \vdots \\
\vdots & \vdots & & \ddots & \vdots & & \ddots & \vdots \\
1 & 2 & \ldots & \ldots & \mathrm{i} & & & \mathrm{i} \\
\vdots & \vdots & \ddots & & \vdots & \ddots & & \vdots \\
\vdots & \vdots & & \ddots & \vdots & & \ddots & \vdots \\
1 & 2 & \ldots & \ldots & \mathrm{i} & \ldots & \ldots & \mathrm{N}
\end{array}\right] \cdot\left[\begin{array}{c}
1 / \mathrm{X} \\
2 / \mathrm{X} \\
\vdots \\
\vdots \\
\mathrm{i} / \mathrm{X} \\
\vdots \\
\vdots \\
\mathrm{N} / \mathrm{X}
\end{array}\right]=\left(\mathrm{V} \mathrm{k}\left[\begin{array}{c}
\mathrm{K} \\
\mathrm{X}_{1} \\
\vdots \\
\vdots \\
\mathrm{X}_{\mathrm{i}} \\
\vdots \\
\vdots \\
\mathrm{X}_{\mathrm{N}}
\end{array}\right]\right.
$$




$$
X_{1}=\sum_{\mathrm{i}=1}^{\mathrm{N}} \frac{\mathrm{i}}{\mathrm{X}}=\left(\frac{1}{\mathrm{X}}\right) \frac{N(N+1)}{2}=1 \text {, and } X_{2}=\frac{1}{\mathrm{X}}+2 \cdot \sum_{\mathrm{i}=2}^{\mathrm{N}} \frac{\mathrm{i}}{\mathrm{X}}=\frac{1}{\mathrm{X}}+2 \cdot\left[1-\frac{1}{X}\right]
$$

and the formula of $\mathrm{X}_{\mathrm{i}}$ can be computed as follows:

$$
\begin{gathered}
X_{i}=\mathrm{i}+\frac{1}{\mathrm{X}} \sum_{j=1}^{i-1} j^{2}-\frac{i}{X} \sum_{j=1}^{i-1} j \Rightarrow X_{i}=\mathrm{i}+\frac{1}{\mathrm{X}} \sum_{j=1}^{i-1}\left(j^{2}-i j\right), \text { Where, } \\
\sum_{j=1}^{i-1} j=\frac{1}{2}(i-1)(i) \quad \text { and } \quad \sum_{j=1}^{i-1} j^{2}=\frac{1}{6}(i-1)(i)(2 i-1) \\
\mathrm{X}_{\mathrm{i}}=\mathrm{i}+\frac{1}{\mathrm{X}}\left[\frac{1}{6} \mathrm{i}(\mathrm{i}-1)(2 \mathrm{i}-1)-\frac{\mathrm{i}^{2}}{2}(\mathrm{i}-1)\right] \Rightarrow X_{i}=\mathrm{i}\left[1-\frac{\left(\mathrm{i}^{2}-1\right)}{6 X}\right]
\end{gathered}
$$

Therefore, the formula that gives the displacement $\mathrm{q}_{\mathrm{i}}$ at the $\mathrm{i}^{\text {th }}$ story is,

$$
\begin{aligned}
& q_{i}=\mathrm{i}\left[1-\frac{\left(\mathrm{i}^{2}-1\right)}{6 X}\right] \times \frac{V}{k} \\
& \mathrm{q}_{\mathrm{i}}-\mathrm{q}_{\mathrm{i}-1}=\left\{\left[1-\frac{\mathrm{i}^{2}-1}{6 \mathrm{X}}\right]-(\mathrm{i}-1)\left[1-\frac{\left.(\mathrm{i}-1)^{2}-1\right)}{6 \mathrm{X}}\right]\right\} \cdot \frac{\mathrm{V}}{\mathrm{k}} \\
& \mathrm{q}_{\mathrm{i}}-\mathrm{q}_{\mathrm{i}-1}=\left(\frac{2 \mathrm{X}-\mathrm{i}^{2}+\mathrm{i}}{2 \mathrm{X}}\right)\left(\frac{\mathrm{V}}{\mathrm{k}}\right)
\end{aligned}
$$

\section{Computing the strain using the finite element method}

$\mathrm{U}(\mathrm{x})$ represents the deflection at $\mathrm{x}$. At $\mathrm{x}=0, \mathrm{U}=\mathrm{q}_{1}$ and $\mathrm{U}^{\prime}=\mathrm{q}_{2}$ and $\mathrm{at} \mathrm{x}=\mathrm{L}, \quad \mathrm{U}=\mathrm{q}_{3}$ and $\mathrm{U}^{\prime}=\mathrm{q}_{4}$.

If $f$ represents the shape function, $f=\left[\begin{array}{llll}f_{1} & f_{2} & f_{3} & f_{4}\end{array}\right]$, the deflection function is, $U=f_{1} q_{1}+f_{2} q_{2}+f_{3} q_{3}+f_{4} q_{4}$, Where, $\mathrm{f}_{1}=1-3 \varphi^{2}+2 \varphi^{3}, \mathrm{f}_{2}=\mathrm{L} \varphi(1-\varphi)^{2}, \mathrm{f}_{3}=\varphi^{2}(3-2 \varphi)$, and $\mathrm{f}_{4}=\mathrm{L} \varphi^{2}(\varphi-1)$.

Now, $\varphi=x / L$ ( $\mathrm{L}$ is the length of the element, height of one story on the shear wall.) If we have a Shear building $\Rightarrow \mathrm{q}_{2}=\mathrm{q}_{4}=0 \Rightarrow$ $\mathrm{U}=\mathrm{f}_{1} \mathrm{q}_{1}+\mathrm{f}_{3} \mathrm{q}_{3}, \Rightarrow \mathrm{U}=\left(1-3 \varphi^{2}+2 \varphi^{3}\right) \mathrm{q}_{1}+\varphi^{2}(3-2 \varphi) \mathrm{q}_{3}$, $\varepsilon_{\mathrm{x}}=\frac{\partial \mathrm{u}}{\partial \mathrm{x}}$, and $\mathrm{U}^{\prime}=\frac{\mathrm{dU}}{\mathrm{dx}}=\theta$, Where:

$\mathrm{u}$ is the displacement in the $\mathrm{x}$ direction, $\mathrm{u}=-\mathrm{y} \mathrm{dU} / \mathrm{dx}$.

- $\mathrm{y}$ is the algebraic distance measured from the neutral axis to the extreme fiber of the shear wall. (N.B. maximum $\varepsilon_{\mathrm{i}}$ is at maximum y)

- $\mathrm{x}$ is the abscissa along the shear wall between the levels (i-1) and $\mathrm{i}$.

$-\varepsilon_{\mathrm{x}}$ is the strain in $\mathrm{x}$ direction.

- $U$ ' is the angle of rotation of the section of the shear wall at level $\mathrm{x}$.

The strain $\varepsilon$ can be computed as, $\varepsilon_{x}=\frac{\partial u}{\partial x}=-y \frac{\partial^{2} U}{\partial x^{2}}$ 
If $\mathrm{y}$ is considered to be positive in the opposite direction of $\mathrm{U}, \Rightarrow>\varepsilon_{\mathrm{x}}=\mathrm{y} \frac{\partial^{2} \mathrm{U}}{\partial \mathrm{x}^{2}}$, $\mathrm{B}=\mathrm{y} \cdot \frac{\partial^{2}}{\partial \mathrm{x}^{2}}\left[\begin{array}{llll}\mathrm{f}_{1} & \mathrm{f}_{2} & \mathrm{f}_{3} & \mathrm{f}_{4}\end{array}\right], \quad$ and $\varepsilon=\mathrm{B} \cdot \mathrm{q}$.

$B$ is a row matrix: $B=\frac{y}{L^{3}}\left[(12 x-6 L)\left(6 L x-4 L^{2}\right)(-12 x+6 L)\left(6 L x-2 L^{2}\right)\right]$, and $q$ is a column matrix $\mathrm{q}(4,1)$, with $\mathrm{q} 2=\mathrm{q} 4=0$

$$
\Rightarrow \varepsilon=\frac{y}{L^{3}}(12 x-6 L)\left(q_{1}-q_{3}\right)
$$

The strain $\varepsilon_{\mathrm{i}}$ at the $\mathrm{i}^{\text {th }}$ story in terms of displacement factor $\left(\mathrm{q}_{\mathrm{i}}-\mathrm{q}_{\mathrm{i}-1}\right)$ is,

$$
\varepsilon_{i}=-\frac{y}{L^{3}}(12 x-6 L)\left(q_{i}-q_{i-1}\right)
$$

By substituting the values of $\left(\mathrm{q}_{\mathrm{i}}-\mathrm{q}_{\mathrm{i}-1}\right)$ from eqn.(8) into eqn.(9), then

$$
\varepsilon_{\mathrm{i}}=-\frac{\mathrm{y}}{\mathrm{L}^{3}}(12 \mathrm{x}-6 \mathrm{~L})\left(\frac{2 \mathrm{X}-\mathrm{i}^{2}+\mathrm{i}}{2 \mathrm{X}}\right)\left(\frac{\mathrm{V}}{\mathrm{k}}\right)
$$

Also, the maximum value of the strain $\varepsilon_{\mathrm{i}}$ between the levels (i-1) and i, i.e. (x $€[0, L])$.

$$
\frac{\partial}{\partial \mathrm{x}}\left[\varepsilon_{\mathrm{i}}\right]=-12 \frac{\mathrm{y}}{\mathrm{L}^{3}}\left(\frac{2 \mathrm{X}-\mathrm{i}^{2}+\mathrm{i}}{2 \mathrm{X}}\right)\left(\frac{\mathrm{V}}{\mathrm{k}}\right)<0
$$

The function $\varepsilon_{i}$ is decreasing which means that the maximum strain in a shear wall, between levels $i-1$ and $i$, occurs at the bottom of the shear wall (at $x=0)$, and this maximum strain from eqn(10) is equal to:

$$
\varepsilon(\mathrm{x}=0)=\frac{6 \mathrm{y}}{\mathrm{L}^{2}}\left(\frac{2 \mathrm{X}-\mathrm{i}^{2}+\mathrm{i}}{2 \mathrm{X}}\right)\left(\frac{\mathrm{V}}{\mathrm{k}}\right)
$$

The maximum strain $\varepsilon_{\mathrm{i}}$ in the entire shear wall is calculated such that,

$$
\frac{\partial}{\partial \mathrm{i}}\left[\varepsilon_{(\mathrm{x}=0)}\right]=0 \Rightarrow \frac{\partial}{\partial \mathrm{i}}\left[6\left(\frac{2 \mathrm{X}-\mathrm{i}^{2}+\mathrm{i}}{2 \mathrm{X}}\right)\right]=0 \Rightarrow \mathrm{i}=1 / 2 ;
$$

So, the function $\varepsilon_{(x=0)}$ is decreasing for $\mathrm{i}>1 / 2,\left(\mathrm{i}_{\min }=1\right)$, which means that the maximum value of strain $\varepsilon_{\mathrm{i}}$ occurs at the lowest point in the first story $\Rightarrow$

$$
\varepsilon_{\max }=6 \frac{y}{L^{2}} \frac{V}{k}
$$

\section{Maximum drift at the top of a shear wall}

The maximum displacement at the top of the shear wall is reached when the reinforcement strain in the tension zone at the lowest section of the shear wall is equal to $\varepsilon_{\text {st }}$ (maximum allowable strain in steel), and the strain in the extreme fiber of the compression zone in the same section is equal to $\varepsilon_{\mathrm{c}}=$ maximum strain limit of concrete in compression $=0.003$. 
So the lowest section in the shear wall, which is the most critical section, is considered to have a triangular distribution.

From eqn(11), $\varepsilon_{\max }=6 \frac{\mathrm{y}}{\mathrm{L}^{2}} \frac{\mathrm{V}}{\mathrm{k}}$,

and from eqn(5) $\mathrm{V}=\frac{3}{2 \mathrm{~N}+1} \mathrm{k} \Delta \Rightarrow \frac{\mathrm{V}}{\mathrm{k}}=\frac{3}{2 \mathrm{~N}+1} \Delta$,

$$
\Rightarrow \varepsilon_{\max }=6 \frac{\mathrm{y}}{\mathrm{L}^{2}} * \frac{3}{2 \mathrm{~N}+1} \Delta=\frac{18 \mathrm{y}}{\mathrm{L}^{2}(2 \mathrm{~N}+1)} \Delta,
$$

where $\mathrm{D}$ is the maximum displacement at the top of the shear wall. From similar triangles of the section:

$$
\frac{\mathrm{y}}{\varepsilon_{\mathrm{st}}}=\frac{\mathrm{x}}{\varepsilon_{\mathrm{c}}} \Rightarrow \mathrm{y}=\frac{\varepsilon_{\mathrm{st}}}{\varepsilon_{\mathrm{st}}+\varepsilon_{\mathrm{c}}} \mathrm{d}
$$

The maximum strain in the shear wall presented in eqn(12) at the level of steel should be smaller than $\varepsilon_{\text {st }}$ :

$$
\begin{gathered}
\varepsilon_{\max }=\frac{18 \mathrm{y}}{\mathrm{L}^{2}(2 \mathrm{~N}+1)} \Delta \leq \varepsilon_{\text {st }}, \text { replace y from eqn }(13) \Rightarrow \\
\Delta \leq \frac{\mathrm{L}^{2}(2 \mathrm{~N}+1)\left(\varepsilon_{\mathrm{c}}+\varepsilon_{\mathrm{st}}\right)}{18 .(\mathrm{d})}
\end{gathered}
$$

If the strain in the steel is to stay below $\varepsilon_{\mathrm{y}}$ (yielding strain), the maximum allowable drift at the top of the shear wall is,

$$
\Delta \leq \frac{\mathrm{L}^{2}(2 \mathrm{~N}+1)\left(\varepsilon_{\mathrm{c}}+\varepsilon_{\mathrm{y}}\right)}{18 .(\mathrm{d})}
$$

In this case, the lowest section of the shear wall behaves as a balanced section; the limits are reached in the reinforcement in tension and in the concrete in compression at the same time, and at that point, the maximum allowable drift at the top of the shear wall is reached.

Notice that, in formula (15) above, as d increases the maximum allowable displacement decreases since any small movement tends to cause larger strain at the bottom section of the shear wall. On the other hand, and as far as maximum displacement is concerned and disregarding economical and architectural issues, it is better to use more number of shear walls with small $d$ than to use fewer shear walls with large $\mathrm{d}$; keeping in mind that the inertia of a shear wall is increased cubically as a function of $d$, and a bigger $d$ will increase the stiffness significantly in a certain direction.

\section{Comparison with different seismic codes and investigators}

The formula proposed by the author is: $\Delta \leq \frac{\mathrm{L}^{2}(2 \mathrm{~N}+1)\left(\varepsilon_{\mathrm{c}}+\varepsilon_{\mathrm{st}}\right)}{18 . \mathrm{d}}$. If the effective depth of the shear wall $\mathrm{d}=2 \mathrm{~m}$, the inter-story length $\mathrm{L}=3 \mathrm{~m}$; also from Figure 3, if $\varepsilon_{\mathrm{st}}=\varepsilon_{\mathrm{y}}=0.00207$ and $\varepsilon_{\mathrm{c}}=0.003$, the formula becomes $\Delta \leq \frac{\left(\mathrm{H}_{\mathrm{t}}+1.5\right)}{1183.432}$, where $\mathrm{H}_{\mathrm{t}}$ is the total height of the building. See Figure 4 for the comparison of this 
formula with the maximum allowable displacement suggested by other investigators.

The allowable displacement (drift) suggested by IBC and UBC are much greater than the others. Also Fintel [12], Searer [13] and Searer and Freeman [14] suggest relatively large value as compared to that given by PS92, and the Lebanese Code. Also, the formula proposed in this work gives comparative results to the PS92 and the Lebanese Code.

Note that most codes give the allowable drift at the top of the building or at the top of a story as a function of the total height or the story height only, while the formula of eqn (15) suggested by the author gives the maximum allowable drift as a function of the height of one story, the number of stories, the effective depth of the shear walls used, and the elastic properties of the materials used in the shear wall (steel and concrete).

The conservative results of the suggested formula is due to the fact that the building analyzed is purely shear building and the compression effects due to vertical loads were disregarded; the vertical compressive force applied on the shear wall helps in the lateral resisting capacity. In addition, constant stiffness is assumed in all the stories, which usually is not the case since shear walls tend to have variable stiffness (stiffer at the bottom and less stiff going up the building).

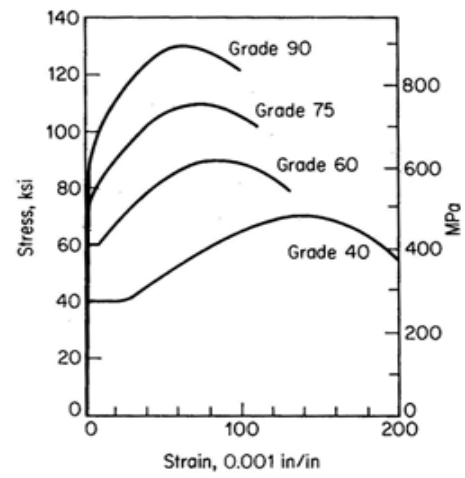

(a)

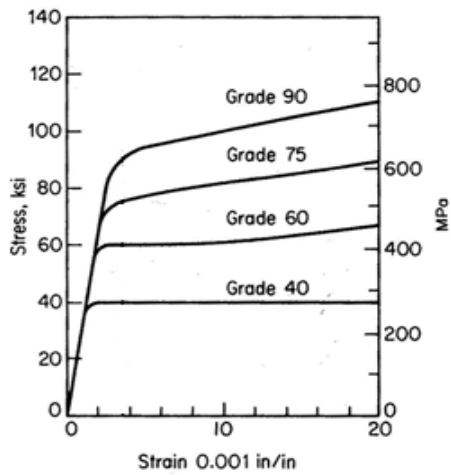

(b)

Figure 3: $\quad$ Typical Stress-Strain Curves for Reinforced Bars [15].

In addition, if the allowable strain in steel $\varepsilon_{\mathrm{st}}$ is considered to be larger than $\varepsilon_{\mathrm{y}}$ (which means that yielding of steel is permitted, or in other words the strain is beyond yield on the yield plateau as in Figure 3 (b)), a larger allowable inter story and overall drift will be permitted. This may be the reason why some codes suggest a larger allowable drift than eqn (15); the structure is allowed to pass the elastic limits and displace within the plastic region taking into consideration dynamic reversals under wind or earthquake loading.

It is also important to note that the formula suggested by the author also provides a good approximation of the drift values for strains that go beyond the elastic limits in the reinforcing steel. 


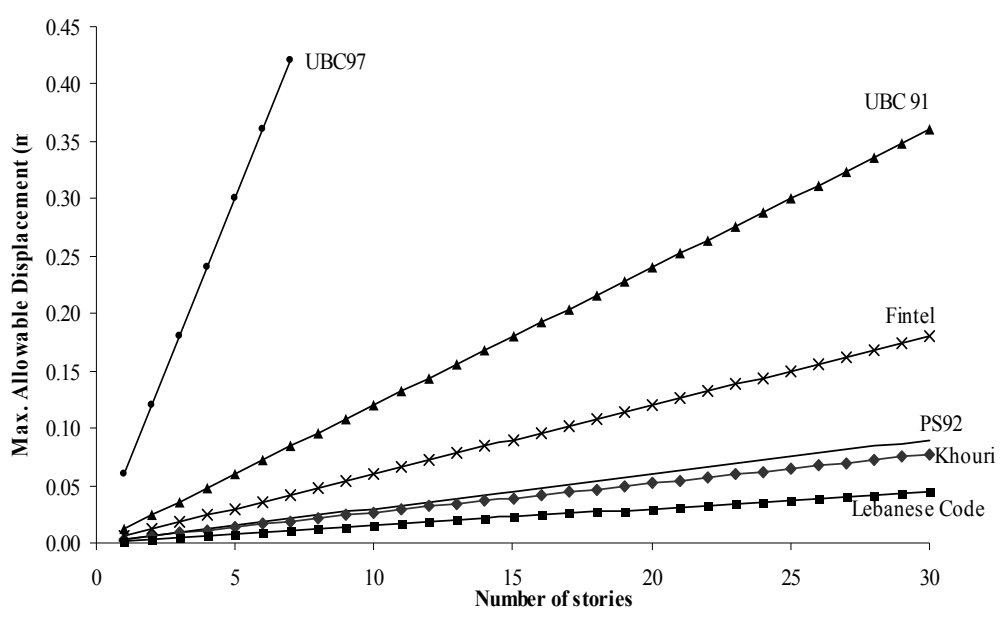

Figure 4: Maximum allowable displacement at the top of a shear wall vs. number of stories for various investigators.

\section{Conclusion}

In this study, shear building was analyzed using the finite element method. The shear was obtained as a function of the displacement. A value for the displacement at any story was obtained, and from which a function for the relative displacement between two stories was then determined. Using the above, an equation for the maximum strain was resolved. A limiting value for the maximum displacement within the elastic limits was obtained as a function of the height of a story, number of stories, depth of tension steel $\mathrm{d}$ in a shear wall, the strain of steel $\varepsilon_{\mathrm{st}}$ and maximum allowable concrete strain. Note that shear building was analyzed like a beam with ignoring vertical loads and assuming constant lateral stiffness in all stories. The author now is in the process of developing a formula that calculates the maximum allowable elastic strain with variable lateral stiffness in all stories.

Comparison between the results of the formula suggested in this work by the author and the maximum allowable drift values suggested by others show that most codes tend to suggest a high maximum allowable displacement at the top of the building or high story drift value; while the formula suggested in this paper tends to give conservative values as compared to most other codes with the exception of the French (PS92) which in some case gives more conservative values than this formula. Also, the Lebanese code gives more conservative values than the suggested formula.

On the other hand, the value h/50 suggested by UBC97 and IBC 2006 can be considered an aggressive suggestion for a shear building in the sense that they generate large strains at the bottom of a shear wall; it is important to note that 
even though the high drift values correspond to a flexible structure thereby lower lateral forces, however such large displacements may be dangerous.

It is now left for the designing engineer to evaluate his structure and decide/choose a maximum allowable strain limit for concrete and for steel, and determine the corresponding maximum allowable drift values.

Finally, the formula suggested by the author can serve as a starting point after which the designing engineer would know that the shear wall in question has passed the elastic limit in a shear building.

\section{Acknowledgements}

The author thanks Optimal Engineering Consulting and Contracting, (OECC) for sponsoring the major part of this work and special thanks to the Lebanese University, Faculty of Engineering, Branch II for sponsoring part of this on going research. Also, thanks to the engineers Bassam Mazloum, Johnny Jreige and Gilbert Abou Zeid who helped in the set up of this paper.

\section{References}

[1] "Uniform Building Code", by International Conference of Building Officials, Whittier, California, 1997.

[2] "International Building Code", IBC-2006 Edition, Published by the International Code Council, INC., 2006.

[3] "Lebanese Code", General Seismic Design Guidelines and Regulations, Beirut, Lebanon, 1997.

[4] Bathe K.J., "Finite Element Procedures in Engineering Analysis", Pentice Hall, Englewood Cliffs, New Jersey, 1982.

[5] Craig, Roy, "Structural Dynamics- An Introduction to Computer Methods", John Wiley and Sons, 1981.

[6] "Uniform Building Code", by International Conference of Building Officials, Whittier, California, 1991.

[7] "Règles Parasismiques Algériennes", RPA-88, Regulation of Algerian Seismic Code, Publication OPU, Algiers, Algeria, 1988.

[8] Règle de Construction Parasismique", Règle PS applicables aux bâtiments - PS 92 Normes NF P 06-013, 1992.

[9] "Standards for Seismic Civil Engineering Construction in Japan", Earthquake Resistant Regulations for Building Structures in Japan, Tokyo, Japan, 1980.

[10] "New Zealand Standard NZS 4203", General Structural Design and Design Loading for Buildings, Daft DZ 4203, Standards Association of New Zealand, Wellington, New Zealand, 1992.

[11] Naeim, Farzad, "The Seismic Design Handbook", Structural Engineering Series, Van Nostrand Reinhold, New York, 1989.

[12] Mark Fintel, "Handbook of Concrete Engineering", Published by Van Nostrand Reinhold Company, $2^{\text {nd }}$ edition, New York, 1985. 
[13] Gary Searer, "Poorly Worded, Ill-Conceived, and Unnecessary Code Provisions", 2006 Annual Meeting of the Los Angeles Tall Building Structural Design Council, pp. 72-85, Los Angeles, 2006.

[14] Gary Searer and Sigmund Freeman, "Design Drift Requirements for LongPeriod Structures", $13^{\text {th }}$ World Conference on Earthquake Engineering, Vancouver, B.C., Paper No. 3292, August 1-6, Canada, 2004.

[15] Arthur Nilson and George Winter, "Design of Concrete Structures", McGraw Hill International, $11^{\text {th }}$ Edition, New York, 1991. 